\title{
IMPROVED METHODS OF PROCEDURE IN CRUISING FOR OPERATING PURPOSES
}

\author{
By N. B. Langballe and I. F. Fogh
}

$\mathrm{A}^{\mathrm{N}}$ N OPERATING cruise must meet two requirements, which unfortunately in practise are rather opposed to each other, namely: Accuracy and cheapness. The volume which may be cut on an operating area, often as small as 300 to 400 acres, must be correctly predicted within a limit of error of about $10 \%$, and the cost of doing the necessary field and office work must, in general, not exceed 7 to 8 cents per cu. $\mathrm{ft}$.

The use of aerial photographs has considerably helped to cheapen operating cruises and to improve maps and information relative to operations in general, but methods of sampling for volume have not quite kept step with mapping technique and are, in general, little different from what they were ten years ago.

It is true that the need for increased intensity as unit areas grew smaller has been recognized, but this need was simply met by closer line spacing and more sample plots per cruise line, with the result that the cost of cruising would have been materially increased had not aerial photographs saved the situation by eliminating the necessity of controls in certain instances and by confining the cruise line system to merchantable areas. For the purpose of the following discussion it is assumed that the usual method of carrying out an operating cruise consists in calipering $1 / 4$ acre sample plots at $10 \mathrm{chn}$. intervals along cruise lines spaced 10 chns. apart, or, in other words, a $21 / 2 \%$ cruise.

During the past two years we have given some attention to sampling methods on operating cruises where aerial photographs were available and have introduced certain changes in technique which we know have effected savings in cost and which we believe have also improved the accuracy of volume estimates.

These changes consist essentially of the introduction of tree counts to replace a certain proportion of calipering on sample plots and of the adoption of a modified strip method of cruising to replace the straight line plot system of the past.

The justification for counting a proportion of the total number of sample plots rather than calipering them $100 \%$ was based on a statistical analysis of available material from past cruises. 


\section{IMPROVED METHODS OF CRUISING-LANGBALLE \& FOGH 85}

This analysis showed that the variation of basal areas in a given stand around the average basal area for that stand, expressed in per cent., was approximately the same as the variation of number of trees per quarter acre sample plot around the average number of trees, also expressed in per cent.

As each sample plot contains a comparatively large number of trees, it is evident that the average basal area is determined with far greater accuracy than is the average number of trees per acre when all sample plots are calipered $100 \%$.

If the probable error of an average decreased in direct proportion to the number of samples the above mentioned relationship would be of no importance. Since the probable error actually decreases in proportion to the square root of the number of samples, it is obvious that the most advantageous distribution of samples would be an equal number for each of the two volume factors under discussion.

This goal is impossible to obtain in practice, due to budgetary consid. erations, but we may at least compromise by sampling as closely to this ideal as is economically possible. As trees are more rapidly counted than they are calipered, the obvious way to effect this compromise is to reduce the number of trees calipered and employ the time thus saved in counting a larger number of trees.

The justification for the adoption of strip sampling in preference to plot sampling was based on the common sense observation that strips run in the irregular stands, with which most of us are dealing, give more representative samples than do plots.

Certain experiments were carried out in the field which consisted in dividing several sample areas into strips and plots each representing $1 / 4$ acre upon which all trees were counted. The variations around the average number of trees per unit area as determined from the $100 \%$ count of the total area were examined for the strips and plots separately and showed considerably less variation from the average in the strips than in the plots.

This result is in complete agreement with what may be expected from strips due to their greater proportion of perimeter to area as compared with plots.

It was furthermore found that most of the time honored objections to strip cruising were completely eliminated by a proper application of the principles discussed above.

A brief outline of the method of cruising for operating purposes decided upon as a consequence of these investigations and carried out on a 50 square mile area during the winter of $1937-38$ may be given as follows: 
$1 / 2$ chn. wide strips were run at 15 chn. intervals by two-man cruising parties. All softwood trees over $4^{\prime \prime}$ d.b.h. were counted along the full length of the strips by means of a tally counter laced to the cruiser's belt. The tree count was recorded on the topography sheet of the field note book at every $5 \mathrm{chn}$. interval for each separate type and for each operating area boundary. Species were not separated in the counting.

$1 / 4$ acre circular sample plots were calipered at $20 \mathrm{chn}$. intervals along the strips recording diameter and species distribution by types. Height measurements were also taken at these sample plots.

Checking was carried out systematically during the entire cruise, the checker carrying an $81 / 4^{\prime}$ pole for the purpose of measuring the width of the strip at all marginal trees.

This method amounts to a count of all trees on $3-1 / 3 \%$ of the total area, supplemented by caliper measurements of all trees on about $1 \%$ of the total area. The cruise is therefore a straight strip cruise with plots inserted at every quarter mile, these plots serving the purpose of sampling diameter distributions, species distributions and heights.

The advantages of the suggested methods of sampling are four in number: (1) A $20 \%$ reduction in cost of the field work due to wider line spacing and slightly increased production per party day definitely established in the cost figures for the above mentioned cruise.

(2) A $14 \%$ increase in accuracy of the cruise derived partly from a better balanced system of sampling and partly from the advantage of strips over plots. This increase in the accuracy has been demonstrated in field measurements of test areas while, so far, only one area of 2,300 acres cruised in this manner has been cut over. The estimate checked within 1 per cent.

(3) The ease and speed with which checking may be carried out introducing a further saving of time.

(4) Greater simplicity and speed of office computations due to the reduction in number of calipered plots.

The objections to strip cruising which have been raised, and the manner in which these are considered to be overcome may be outlined as follows:

(1) Higher cost of strip cruising due to the necessity of using a threeman party, when trees are to be calipered along the strips. This objection has been overcome by counting on the strips and restricting the calipering to $20 \mathrm{chn}$. spaced sample plots retaining the efficiency of the two-man party.

(2) Higher cost due to less production per party day. This has also been overcome by counting, and it was demonstrated last winter that the production actually is slightly greater than by the old method of cruising. 


\section{IMPROVED METHODS OF CRUISING-LANGBALLE छ FOGH 87}

(3) Inaccuracies in sampling of marginal trees due to greater perimeter of strips in proportion to their area. Very thorough checks last winter demonstrated that, with a few days' experience in counting trees on a 33' wide strip, the cruiser is able to obtain better results than in calipering trees on circular sample plots, due to the comparatively narrow width of the sample area and the straight boundaries as compared with the wide radius and curved boundary of the circular sample plot. The greater perimeter of the strips, furthermore, tends to give better and more representative sampling, as much greater variety of conditions is covered by the sample areas than in the line plot system.

(4) The cruiser's time is too occupied with continuous sampling, and his impression of topography and operating conditions is consequently not as vivid as in line plot cruising. This objection does not hold good in practice, as the cruiser stops along the strip at frequent intervals to enter data in his field book namely, whenever he crosses a height of land, whenever the type changes, at every $5 \mathrm{chn}$. interval, and finally every $20 \mathrm{chns}$. for the purpose of calipering a sample plot and taking height measurements. He has therefore ample opportunity to size up topographic as well as operating conditions within the country through which he is travelling.

(5) Checking of strips run in the summer time is difficult and not $100 \%$. This is the only objection which has not been completely overcome but, as practically all cruising is carried out in the winter, it is not of any great importance. The disadvantage may probably be overcome in the summer time by blazing a tree at every $5 \mathrm{chn}$. interval along the line, which should be enough to enable the checker to stay on line when running a compass course along the same bearing as the original line.

In conclusion it should be emphasized that the purpose of this article is primarily the presentation of certain fundamental principles which are of special importance in cruising small areas.

The particular method of cruising described above is an adaptation of these principles which happened to suit the conditions and requirements of the cruise in question.

The fundamental idea behind these suggested methods of sampling may of course be utilized in various manners to formulate systems of cruising which will suit a variety of conditions, and it is hoped that it may be an incentive to bring about a more thorough analysis of the various factors entering into volume estimates before commencing the cruise of any one area. 